\title{
Reflections of the Establishment with Policy - based Medical Liability Insurance
}

\author{
Gang Wang ${ }^{1,2, a}$, Shouwen, Wang ${ }^{1, b}$ \\ ${ }^{1}$ College of Law and Public Administration, China Three Gorges University, Yichang 443002, \\ China; \\ ${ }^{2}$ Yichang City People 's Hospital,Yichang,443002, China \\ a121250865@qq.com; 425432368@qq.com
}

Keywords: medical insurance model, policy medical liability insurance.

\begin{abstract}
There are two main modes of implementation of medical liability insurance in China: compulsory mode of implementation and voluntary insurance. From the current level of development of China's insurance industry, the nature of medical institutions and their insurance awareness, etc. These two kinds of insurance mode still cannot fundamentally change the long-term insurance coverage rate low problem. This shows that in the implementation of medical liability insurance model, it is necessary to make new choices. This paper analyzes the current situation of the development of medical liability insurance in China from the origin of medical liability insurance, and analyzes the advantages and disadvantages of the implementation model of existing medical liability insurance. Finally, the policy of medical liability insurance is the most ideal model at present.
\end{abstract}

\section{Introduction}

The establishment of medical liability insurance system can produce greater economic and social benefits, and can realize the hospital, patient, insurance company these three parties win-win situation. It can not only create a harmonious medical environment to alleviate the current tension in China's doctor-patient relationship, can also increase the enthusiasm of health care workers to participate in the work more to expand the insurance company's capital flows, in order to achieve the purpose of expanding business revenue. At present, China's insurance industry development status, policy-oriented medical liability insurance model is the best insurance model.

\section{The origin of medical liability insurance}

US medical protection company in 1899 to provide the first medical liability insurance policy. The development of medical liability insurance has been accelerated by the increasing awareness of people's own rights. In the first 50 years of the term of medical liability insurance, the United States had cases of medical negligence litigation. According to statistics, In the 20 years since 1840, the number of US States courts undergoing malpractice lawsuits has increased by as much as 950\%[1].The origins of medical liability insurance have benefited from public litigation against medical negligence, and medical liability insurance has been fully developed over the next century. In the scope of the protection of medical responsibility, the terms of the policy, insurance rates, the amount of responsibility and other aspects of the formation of a sound system and a unified specification. Medical liability insurance in different countries in the West to form a different model, there have been different problems, but also have a more rapid development, In particular, it has made a great contribution to the protection of the rights and interests of victims, and has made great breakthroughs in the interests and reputation of medical institutions.

China's medical liability insurance started relatively late compared with the western developed 
countries. In 1989, China's first medical liability insurance policy was issued by the People's Insurance Company of China, Guangxi Yi Ning County Branch. Then, Beijing, Shanghai, Shenzhen and other major cities have also carried out a positive medical liability insurance pilot work. China introduced the first nationwide medical liability insurance clause is 2000 China People's Insurance Company to declare the "medical liability insurance clause." At present, PICC, security and other insurance companies are involved in the medical liability insurance business. In 2002, the medical malpractice regulation was promulgated, which indicates that a new round of medical liability insurance has been popularized all over the country, the malpractice of the medical malpractice case exposes the malpractice of the medical liability insurance regulations, which makes the insurance companies have its implementation of the medical liability insurance terms have been improved. In 2006, "the State Council on the development of the insurance industry in a number of development views" for the medical liability insurance, pointed out: "The medical liability insurance should form a nationwide unified medical liability insurance system through the establishment of pilot projects in all regions and cities, and speed up legislation." But China has not yet formed nationwide coverage of unified medical liability insurance system, only in some developed areas to implement the pilot work.

\section{China Medical liability insurance development status}

Medical liability insurance China the development started late, in recent years with the doctor-patient contradiction intensifies, many domestic provinces and cities have introduced the medical liability insurance, hoping to transfer medical occupation risk, reduce the burden of medical institutions, and reduce medical disputes. This insurance company also developed medical liability insurance products, but because the insurance companies offer these services cannot meet the medical needs of the organization, and therefore did not get a positive response in medical institutions of this product. The China currently insured status, being the most hospital domestic insurance company launched the product performance is not positive, most insurance companies are in line with the perspective of profit maximization introduction of medical liability insurance to make health insurance, the terms of the contract are not conducive to the hospital, once encountered medical disputes the insurance company does not make specific solutions the ultimate responsibility is borne by the hospital, rather than for the hospital to solve practical problems, eventually leading to the hospital for medical liability insurance is not a positive attitude.

The insurance company is pointed out, the process of medical process for medical professional strong, once disputes encountered insurance companies lack even related professionals not only understand medicine and understand the law, to resolve disputes between doctors and patients so that you do not like the developed countries medical Liability Insurance Company can for medical institutions to provide professional legal services so strong. And if the insurance companies set up independent medical compensation experts' team, it will greatly increase the premium, such high premium is not a few hospitals can afford.

In view of the negative attitude towards the medical liability insurance and the lower premium income of the insurance companies in the current medical institutions, there is a lack of enthusiasm for the promotion of medical liability insurance. Some domestic scholars and people in the field suggest that compulsory medical liability insurance should be implemented. [2] Ma Mingzhe proposed in the proposal of the CPPCC meeting, in order to promote the sustained and healthy development of China's medical and health undertakings, a compulsory medical liability insurance system should be established. However, some scholars hold the opposite attitude, and they point out that the dual track system should be implemented mainly with voluntary insurance as the main and compulsory insurance as the supplementary. Medical liability insurance should rely on the power of the market to make a natural deduction rather than rely on the government's coercive power to push it forward. Once the administrative strength is weak, the insurance will be a serious rebound phenomenon, it will affect the development of the medical insurance industry, and even 
retrogression. [3]

In a word, we insist on the value of medical liability insurance system and combine the social benefits and insurance principles to compare and analyze the pros and cons of compulsory insurance and voluntary insurance.

\section{Analysis on the Advantages and Disadvantages of the Implementation Model of Existing Medical Liability Insurance}

In fact, the direction of a national health insurance implementation model and the country's economic development environment and health care system structure has a great relationship. In the current stage of the development of medical liability insurance in China, there are two modes of implementation of the main medical liability insurance: compulsory mode of implementation and voluntary insurance.

\section{1 compulsory medical liability insurance implementation model}

The most important responsibility for compulsory liability insurance is to protect the rights and interests of the victims, make up for the loss of the victim, and then the risk of medical liability of the scattered medical institutions.

\subsubsection{Advantage analysis}

(1) contribute to the realization of public interest

Now, the protection of the medical liability insurance is paid more and more attention. The liability insurance is regarded as the third party benefit contract, and the legal system that gives the third person the direct claim to the insurer is gradually formed. The implementation of compulsory insurance in medical liability insurance is conducive to making up for the shortcomings of voluntary insurance in protecting the interests of victims. Medical liability compulsory insurance reflects the government's value orientation, that is, to protect the interests of the majority of patients, but also to promote sustained healthy development of China's medical and health undertakings.

(2) to help control risk and improve management experience

One basic rule is that the level of insurance coverage often determines whether the insurance company can effectively spread the company's business risk. Mandatory medical liability insurance can guarantee both effective and effective promotion of insurance company to improve product development and management experience. First, the insurance company can reduce the risk of lower operating insurance risks; Second, the insurance company can accumulate experience, statistical analysis of the data for the insurance liability insurance and liability reserve to provide support; Again, you can improve the insurance company In dealing with medical disputes in the ability to truly promote the cultivation of medical liability insurance market.

\subsubsection{Disadvantage analysis}

(1) low liability limit, narrow coverage

Most scholars agree that the idea is to reduce the amount of insurance coverage and its coverage as much as possible to expand. First, the trend to increase the amount of medical liability is inconsistent with the low liability limit. In order to preserve the coverage of medical liability insurance, the limitation of liability for compulsory insurance cannot be set too high, and the country is gradually showing the increase in compensation for victims of medical malpractice, which forms a contradiction. Secondly, the mandatory responsibility for a wide range of requirements, the need for government enforcement. The way of protecting the coverage of medical liability insurance under different medical institutions and how to link the information sharing and cooperation of the competent departments. Which to a certain extent, increased the government regulation and supervision of medical liability insurance administrative costs and difficulty.

(2) Be not conducive to insurance companies competition

In fact, in the competition, the survival of the fittest, competition is a powerful driving force for development. The core of the market economy is competition, in the perfectly competitive market, social welfare will be maximized. The compulsory insurance is the government to use 
administrative means to intervene in the market behavior, undermine the market fair competition model. And medical liability compulsory liability insurance undermines the game between medical institutions and insurance companies. The lack of competition between insurance companies in the status quo, and thus the lack of core competitiveness, once the impact of outside insurance companies will make it difficult for local insurance companies to stand. This isn `t conducive to the healthy development of medical liability insurance market.

\subsection{Implementation model of voluntary medical liability insurance}

\subsubsection{Analysis on the Advantages of Voluntary Medical Liability Insurance Model}

(1) to promote the cultivation of medical liability insurance market

The complete market-oriented behavior has the advantages of market supply and demand mechanism, competition mechanism and price mechanism. Voluntary medical liability insurance model for the development of insurance companies, the market competition environment will make insurance companies compete with each other, the survival of the fittest, to stimulate the insurance companies continue to pursue higher quality, to provide customers with more quality policy. Finally, the voluntary health insurance model will stimulate the market to form a system of medical liability insurance price system.

(2) to reduce government and social pressure

The compulsory insurance model increases the cost of government monitoring and management of this insurance. And the voluntary insurance model can effectively avoid the implementation of the model due to poor government supervision caused by the huge flaws in the insurance system. To the market only invisible hand, the government only see the hands of the auxiliary, which reduces the government administrative costs.

\subsubsection{Analysis of the disadvantage of voluntary insurance model}

(1) voluntary insurance is easy for medical institutions to reverse behavior

Medical institutions and departments in the risk of high and low probability of different risk probability of the departments of the insurance will have a different reflection. This will gradually form a medical institution and the adverse choice of medical liability insurance. This kind of adverse choice will make the insurer blindly raise the insurance rate, but when the rate reached a certain amount, the insurance will become less meaningful.

(2) voluntary reduction of medical institutions is not conducive to the promotion of social welfare

Insurance as a kind of economic system, with the characteristics of continuity, not a short time contract. At the same time, it is also a system based on the national economy, which plays a very important role in the promotion of the national economy and the total social welfare. Assuming that social welfare equals the sum of the expected utility of the subjects, the risk will be increased from the subject with a higher degree of risk aversion to the subject with lower risk aversion. Because such a transaction can make both the expected utility of both. [4] medical institutions are risk aversion, the insurer is a risk-neutral, the medical practice risk from the medical institutions to the insurance company will increase the total social welfare. [5] If you take the original insurance model, the medical institution is very easy to make the wrong decision to buy insurance, therefore, the health insurance insurance to take the form of voluntary insurance is unlikely to achieve the total social welfare benefits.

To promote the evolution of medical liability insurance model when the use of market power or administrative power is mandatory and voluntary between the two main contradictions. In this evolution process, the author set up a policy of medical insurance has a certain analysis.

\section{Reflections on the Establishment of Policy - based Medical Liability Insurance}

The policy insurance is the policy support which the government gives concerned about the people's livelihood insurance policy from the macro level in order to achieve a policy of the purpose. Export credit insurance and agricultural insurance are two major parts of domestic policy insurance. 
From the concept of policy insurance, does our country has the necessity and conditions about establishment of policy-oriented medical liability insurance in the field of medical liability insurance now? Drawing on the development of medical liability insurance abroad,the China's demand for the insurance is urgent.

\subsection{The necessity to establish a policy of medical liability insurance}

(1) The ambiguity of China's medical risk commitment main body to the division

At present, the main body of China's medical responsibility is the hospital itself, and the insurance company accepts hospital's insurance. But the insurance company is not directly involved in the handling of disputes in the event of medical disputes, which resulted in the division ambiguity of medical responsibility. Medical institutions is not only the insured, and in the face of insurance compensation, but also the main body of risk commitment, however,the insurance company dose not assume any risk of medical responsibility only as a profit agency.The responsibility of "vacuum" is bound to bring great obstacles to practical promotion of policy health insurance. In the United States, for example, insurance companies directly involved in the handling of medical disputes and direct compensation. this approach that the medical institutions and insurance companies are as a common medical risk commitment main body, effectively avoids the insurance company's profitability as the only Purpose of participation to the extent.

(2) The current asymmetry of civil relations in Chinese medical behavior

As we all know, the current Chinese law provides that medical institutions may not refuse the patient's treatment. From a legal point of view, the medical behavior of medical institutions is not equal civil relations. However, dealing with medical disputes and compensations is in full accordance with the civil compensation procedures and principles. The asymmetry of this civil relationship has a negative impact on the enthusiasm of medical institutions to buy insurance.

(3) The insured person has a high probability of occurrence of risk

In this era, whether it is China or developed Western countries, and no matter how high skilled doctors and advanced equipment, the medical risk is always unavoidable. A little slip will cast a big mistake in the face of life because of the particularity of the medical profession. So the risk runs through from the beginning of the diagnosis and treatment to the final rehabilitation in the medical industry. There are many uncertain unknown areas of medical services, which will inevitably bring higher risk. Coupled with the particularity and complexity of the human body structure of each person will also make some of the treatment and drugs in use have variety of unpredictable risks.

In general, the current Chinese medical liability insurance has been difficult to adapt to the needs of patients, medical institutions and society, which will inevitably require the government's intervention and guidance to establish policy-oriented medical liability insurance.

\subsection{Feasibility analysis of policy-based medical liability insurance model}

(1) Medical disputes are very harmful

Medical behavior is related to human life and health. Once the occurrence of medical malpractice is a direct threat to the patient's health and even life. And the vicious behavior causes mental and physical damage to medical staff because of patient families's understanding. The consequences will be very serious. If the hospital can not afford the medical negligence and bankruptcy,that will directly affect the stability of hospital health care practitioners and their enthusiasm and will have a huge impact on the local people's medical treatment. We can imagine that the medical risks cause great harm.

(2) The applicant's limited ability to pay compensation and bear the capacity

In recent years, medical disputes are common and the claimed amount is an upward trend, which gives the insured a huge financial burden. Meantime, China's medical claims amount of millions cases increase significantly. In 2002, the Chinese Hospital Management Institute conducted a survey of 326 hospitals in the country. In 2000, the total amount of medical claims in the 326 hospitals was about 60 million yuan, of which $11.5 \%$ were in the amount of more than 1 million yuan, an average of about 210 thousand yuan per hospital. [6] 
(3) The government provides financial support and tax incentives

The development and appearance of medical liability insurance is not long in China. Although there are many current problems, we can see its future social benefits is enormous. At current stage, both the central financial and local financial have enough economic strength give encouragement and support to the healthy development of medical insurance through reducing taxes for the medical institutions, direct purchase of insurance, direct subsidies to medical institutions, etc. [7]

\subsection{Some Thoughts on Popularization}

(1)Enriching product structure

China's medical liability insurance products have less variety, a narrow range, the terms of rough design,and can not meet the needs of social economy and different needs. In the $4 \%$ liability insurance business, there are very few medical liability insurance with millions of people's vital interests. Although Insurance companies have a certain division on the risk of different medical institutions and departments, it is not meticulous, and therefore cannot be reflected on the premium, which is very easy to produce premium and risk of unequal problems. In view of this situation, the insurance companies should broaden the width of the medical liability insurance business, increase innovation, accelerate the upgrading of products and enrich product structure to make different medical liability insurance products for each department to meet their needs.

(2) Pay attention to and solve the "claims difficulties" problem

The insurance industry is on rise for a few years in China, so there are a lot of problems. The most prominent problem is difficult to claim. There are also such problems even if policy insurance is implemented. The reason is that the insurance companies' procedures are so redundant to handle claims that medical disputes cannot be dealt with in time, affecting the insurance effect. Having a set of scientific, impartial and objective assessment of compensation system to handle medical disputes timely, convenient and efficient can solve the problem.

(3) Raise the amount of compensation

The current medical liability insurance limit is too low, so the hospital's compensation risk cannot be effectively passed on so that the hospital did not have the insured enthusiasm. Therefore, we need to improve the insurance company's medical liability limit in order to really play the role of the transfer medical liability risk [8].

(4) Develop a reasonable difference rate

China's current differential rate system is imperfect, not clear. From the actual point of view, developing a reasonable rate of differential is necessary. Insurance companies should develop the applicable difference rate according to different medical institutions, departments, surgical and technical level, and hospital management capacity.

(5) Increase publicity efforts

It is also of great significance to promote the work of policy medical liability insurance. We need to create a good environment through the existing network, television and other media tools. Promoting the medical liability insurance for policyholders is necessary, so we should encourage hospitals and medical personnel to participate in training on medical liability insurance to clarify responsibilities and interests and to enhance insurance awareness.

\section{References:}

[1] James C.Mohr,PhD: 《American Medical Malpractice Litigation in Historical Perspective》 JAMA. 2000:283:1731-1737.

[2] Wei Song: 《On the development of medical liability insurance》, 《Insurance Research》 2003 the seventh period; Jiang Yi: 《medical liability insurance history, status and future》, 《China Insurance Management Institute》 2004 No. 5; Zhu Yifei: 《medical responsibility glass fiber status and prospects》, 《Shanghai Insurance》 2005 the fourth period. 
[3] Chen Shaoxui, Yuan Jie. 《Medical liability insurance: compulsory or voluntary - realistic mode of choice》, 《Shanghai Finance》2005 the twelfth period.

[4] Guo Zhenhua: 《liability insurance: market failure, legislative enforcement and to the risk management》, 《financial theory and practice》 2007 the second period.

[5] Tan Xiangyu, 《medical liability insurance research》, Shanghai University of Finance and Economics Press, August 2008 first edition, p. 81.

[6] Shen Shuguang, Xiao Shangfu. China's compulsory medical liability insurance thinking [J]. Shanghai Insurance 2006, (2): 21-23.

[7] Luo Xiangming. Establishment of compulsory medical liability insurance to adapt to the medical system reform [J]. Hospital leadership decision reference, 2006, (1): 39-42.

[8] Wu Haibo, Jiang Lesheng. Research on the implementation of medical liability insurance model [C]. China Health Care Industry Management, Issue 01, 2012. 